\title{
Smart cities and transport infrastructures topical collection
}

\section{Smarter transport and smarter transport infrastructure for a smarter city}

\author{
Laurent Carnis
}

At present, the smart city is the object of an important and growing body of scientific literature $[1,12]$. One result of that broad movement embracing that specific issue is the existence of numerous debates, different definitions of what a smart city is and its implications are.

The concept of the smart city rests upon different pillars, and smart transport and transport infrastructure is one of them ([10], p. 286). Smart transport and smart transport infrastructure contribute to the building and designing of a smart city by making it more valuable (with a fluid and non-congested traffic), livable (less noisy, free of accidents), more connected (internet networked) and interconnected (stations becomes kinds of cities inside city). A smart city will change the governance of a city as it influences the cooperation among stakeholders acting in the transport field.

Smart city, smart transport and smart transport infrastructure appear to be a promising evolution but some scholars alert with some critics, concerning potential reinforcing inequalities and segregation effects ([3], pp. 21-24). The smart city, smart transport and smart transport infrastructure have to be fully understood as a political project, implying many issues such as ideologies, urban planning, governance, coordination among actors, etc.

Six different papers constitute this topical collection on Smart Cities and Smart Transport Infrastructures. They cover mainly the important issues related to smart city, smart transport and smart transport infrastructure. Some brief overviews are proposed below. They constitute a modest contribution to the literature existing on that issue, but a true one with new findings and results issued from different fields of research. That give a

Correspondence: laurent.carnis@ifsttar.fr

UPE, AME-DEST, IFSTTAR, Marne-la-Vallée, France pluralistic point of view of what is smart transport and smart transport infrastructure.

Heddebaut and Di Ciommo [8] provide a good illustration of the existing links between smart city and smart transport, and here, with the case study of Euraflandres, their potential hybridization. Already mentioned by Nam and Pardo [11], a smart city involves also non-technological sides such as organization and management dimension. It involves leadership inside organization to sustain the project, requires policy integration at different layers, the integration of larger context such as urban policy, economic consideration and some interactions between actors and organizations, etc. Euraflandres constitutes a good example of smart city resting upon an intelligent planning and urbanism coupling transport facilities and other services provided to the population. Heddebaut and Di Ciommo show convincingly the development and the conception of interchange transport infrastructure, which became intertwined and conceived with other services and business facilities. Euraflandres has become an important node in Lille region, providing efficiently transport functions (intermodality, connections, etc.) coupled with other services while using the available space intelligently. That smart city rests upon mainly on smart transport infrastructure, open to new technologies able to provide new services to the population (internet access, networked connected things, comfortable designed spaces, etc.). Another issue highlighted by the authors remains the on-going and permanent coordination among stakeholders, which is possible because of a political room for exchanging and deciding collectively (committees, planning activities, etc.).

$\mathrm{Li}$ and $\mathrm{Yu}$ [9] show in their contribution how freight apps can reduce $\mathrm{CO}_{2}$ transport emission. Globally such apps make possible a better match between supply and 
demand of freight transport for interurban and urban freight transport. The freight apps have to be interpreted as an ICT application that provides "freight distribution, management, and other services for freight stakeholders" (ibid. p. 36). One main expected outcome among others (higher profit, higher use of capital, higher level of service for consumers, etc.) is the contribution to a better livable city by contributing to the reduction of atmospheric pollution. The ICT is an integrating technology driving to a reduction of transaction costs between actors that then can be more efficient and a better fleet management and optimization. With the spreading of freight apps, it is expected that real-time navigation and route planning strengthen the average utilization of vehicles on laden trips, scale economies and a reduction of energy consumption and pollution. However, as the authors emphasize it, it is not a magic solution. It requires a well-designed framework involving different scales (vehicles, loads, company, supply chain and freight network). For being effective, such an app has to be well spread among the different freight stakeholders (to constitute a real network) for being efficient, because it is a network service or club good. It raises also some concerns related to its price, acceptance by the user and its utility for the industry.

The spread of the electric bikes (e-bikes) use can promote a smart velomobility, by making possible a "sustainable, active, and networked mode" of transport, which also could be part of connected vehicles [2]. Arsenio, Dias, Lopes and Perreira examine the potential and barriers to the use of e-bikes by students. Through a questionnaire and a stated-choice experiment with students issued from two secondary schools in Águeda, the authors are able to provide crucial information concerning the barriers to a spread of such innovation, but also the attributes, which are valuable for the potential users. Topography and available cycling lane and infrastructure are the main barriers for using a bicycle to go to school. Those constraints emphasize the involved mixed dimensions of cities (physical and virtual infrastructure ones) and the necessity to be able to couple them. Harrison and Donnelly [7] showed already the city can be conceived as an information one with different layers (social systems, services, resources, infrastructure and natural environment). Arsenio and her coauthors explain that a connected bike could also be an opportunity for pupils for using alternative mode of transportation to the motorized one, but it implies some issues related to the cost and the information service provided have to be solved first.

Stave and Carlson's contribution [13] shows that innovation brings positive evolution, but also new risks requiring smart answer from the stakeholders and city bodies. Indeed electric vehicle is presented as an important tool for reducing pollution and contribute to better air for cities and health for the citizen. However, road crash and other hazards bring new risks in terms of electric shocks for firefighters and people, battery leakage, fire in garage and vehicle under water. The authors performed some interviews with firefighters from Swedish cities and with some officials. The results of their study show that there is a problem of knowledge about risk, disseminating the crucial information among the stakeholders, but also the absence of a clear strategy about the duties and responsibilities. In some way, cooperation and preparedness has to be strongly improved to insure electric vehicle could contribute to a safer city and create value. Smart transport and smart city are a knowledge tool [5]. As Edvinsson emphasizes: “... a knowledge city is purposely designed for encouraging and nourishing the collective knowledge, ie. Intellectual capital, as capabilities to shape efficient and sustainable actions of welfare over time" (ibid. p. 7). The authors who mention the "need for more resources in the form of knowledge, tools, and training" ([13], p. 25) highlight the importance of knowledge dimension. Another crucial issue concerns the need of building a well-designed governance system to handle that problem. For instance, they write: "Another obstacle to greater preparedness for EV risks and safety issues was the lack of horizontal consultation between diverse stakeholder organizations, such as the emergency services, municipalities, police, ambulance services, vehicles scrapping enterprises and car recyclers". (ibid) Smart transport innovation requires well preparing the management and the policy side of innovation [11].

Electric vehicles require an appropriate charging infrastructure location. That issue is the topic investigated by Efthymiou and his coauthors [6]. That contribution explains the different stakes related with the appropriate location of such charging stations. It is a crucial element for spreading the use of electric vehicles and to make that alternative vehicle a success. Smart transport with low noise annoyance, low pollution emission requires a smart land planning and optimization for choosing the location. The authors then propose to develop and apply an algorithm, which means smart city implies the production and the collection of data, their analysis and the use of sophisticated tool. Smart city means smart people too! [10] A smart transport system is a necessity for having an agile society, able to adapt to different evolutions. As mentioned by Efthymiou and his coauthors: ..."constant changes, in the population size, market trends, environmental factors and other elements create the need for relocation, extension and adaptation of facilities in order to ensure that they meet the needs at all times" (ibid, p. 27). The case of Thessaloniki (Greece), investigated by the authors, is particularly illustrative with a 
low penetration rate of electric vehicle but that is expected to grow. With only 15 stations, $80 \%$ of the demand could be served. The authors suggest that implementing these 15 stations would be a decent policy decision.

Smart city and smart transport imply also an ability to produce up-dated and valuable information. Harrisson and Donnelly ([7], p. 6) explain that a smart city, here a smart transport system, provide a new way for observing in details the behaviors and the choices of individuals. Smart cities and smart transport infrastructure become complex systems, which have to be though as such. Ebendt and Tcheumadjeu's contribution [4] shows the importance of knowledge and the necessity of having an appropriate decision support tool for that purpose. Their paper tries to answer such a stake by proposing an approach through a dynamic location referencing.

Smart city and smart transport infrastructure highlight many new issues and challenges for society at large. First, smart city and smart transport infrastructure require a well-designed governance system and appropriate organizations and institutions, which the ultimate goal is to serve the population (citizen driven project) [10]. A well-aligned system of cooperation among stakeholders appears as a crucial issue for having an efficient and effective smart transport system. Second, there are issues related to justice and equity. The spread of new internet connected things, the systematic collection of individual data and the new uses of big data raised potential dangers for privacy and individual liberties. Smart transport has not to become a big brother system, with systematic supervision of individuals and individual choices. The development of high technology systems also should be inclusive and not exclude less technologically oriented population groups benefiting from the advantages and progress. Third, the building of a smart city with smart transport requires a lot of money and resources. That evolution could imply the involvement of private sector at a larger scale raising the remaining room for public intervention. That could mean also a redefinition of public-private association for building, managing, operating and owning crucial (transport) infrastructure. Smart city, smart transport and smart transport infrastructure participate to a change of the face of the city. Here there are a large avenue and some perspectives for new research for having a city and transport more efficient, more livable and more inclusive.

\section{Competing interests}

The author declares that he has no competing interests.

\section{Publisher's Note}

Springer Nature remains neutral with regard to jurisdictional claims in published maps and institutional affiliations.
Received: 15 May 2018 Accepted: 15 May 2018

Published online: 15 June 2018

\section{References}

1. Alibino V, Berardi U, Dangelico RM (2015) Smart cities: definitions, dimensions performance and initiatives. J Urban Technol 22(1):3-21

2. Arsenio E, Dias JV, Lopes SA, Perreira HI (2018) Assessing the market potential of electric bicycles and ICT for low carbon school travel: a case study in the Smart City of Águeda. Eur Transp Res Rev 10:13

3. Breux S, Diaz J (2017) La ville intelligente. Origine, définitions, forces et limites d'une expression polysémique, INRS, p 31

4. Ebendt R, Tcheumadjeu LCT (2017) An approach to geometry-based dynamic location. Eur Transp Res Rev 9:38

5. Edvinsson L (2006) Aspects on the City as a knowledge tool. J Knowl Manag 10(5):6-13

6. Efthymiou D, Chrysostomou K, Morfoulaki M, Aifantopoulou G (2017) Electric Vehicles Charging Infrastructure Location: A Genetic Algorithm Approach. Eur Transp Res Rev 9:27

7. Harrison C, Donnelly A (2011) A theory of smart cities, Proceedings of the $55^{\text {th }}$ Annual Meeting of the International Society for the Systems of Sciences, $\mathrm{p} 15$

8. Heddebaut O, Di Ciommo F (2017) City-hubs for smarter cities, the case of Lille "EuraFlandres" interchange. Eur Transp Res Rev 10:10

9. Li Y, Yu Y (2017) The use of freight apps in road freight transport for $\mathrm{CO}_{2}$ reduction. Eur Transp Res Rev 9:36

10. Nam T, Pardo TA (2011a) Conceptualizing Smart City with dimensions of technology, people, and institutions, The Proceeding of the $12^{\text {th }}$ Annual International Conference on Digital Government Research, pp 282-291

11. Nam T, Pardo TA (201 1b) Smart City as urban innovation: focusing on management, policy, and context, Proceedings of the $5^{\text {th }}$ International Conference on Theory and Practice of Electronic Governance, pp 185-194

12. Söderström O, Paasche T, Klauser F (2014) Smart cities as corporate storytelling. City 18(3):307-320

13. Stave C, Carlson A (2017) A case study exploring firefighters' and municipal officials' preparedness for electrical vehicles. Eur Transp Res Rev 9:25

\section{Submit your manuscript to a SpringerOpen ${ }^{\mathcal{O}}$ journal and benefit from:}

- Convenient online submission

Rigorous peer review

- Open access: articles freely available online

- High visibility within the field

- Retaining the copyright to your article

Submit your next manuscript at $>$ springeropen.com 